\title{
EFL learners' strategy use during task-based interaction in Second Life
}

\author{
Julian ChengChiang Chen \\ Curtin University
}

\begin{abstract}
Motivated by theoretical and pedagogical concerns that the link between second language (L2) learners' second language acquisition (SLA) and language use in 3D multi-user virtual environments (MUVEs) is still not fully connected in current SLA literature, this study examined the patterns of English as a foreign language (EFL) learners' employment of communication strategies during task-based interaction in Second Life (SL). Nine adult EFL learners worldwide were recruited, and they used their avatars to negotiate meaning with peers in interactional tasks via voice chat in SL. Results reveal that confirmation checks, clarification requests, and comprehension checks were the most frequently used strategies. Other types of strategy use were also discovered, such as a request for help, selfcorrection, and topic shift - accompanied by a metacognitive strategy and spell-out-theword that had not been previously documented in task-based research in 3D MUVEs. This study demonstrated that SL could offer an optimal venue for EFL learners' language acquisition to take place and prompt their cognitive processing during task-based interaction. Additionally, 3D multimodal resources afforded by SL provide additional visual support for EFL students' input acquisition and output modifications. A call for more research on voice-based task interaction in 3D MUVEs is also needed.
\end{abstract}

\section{Introduction}

The ubiquity of digital technologies, as manifested in mobile applications (apps), social networking, online gaming, cloud computing, has transformed the way we think, learn, work, and communicate in the 21 st century. In the current English as a foreign language (EFL) teaching/learning paradigm, the disconnect between EFL students' learning styles and interests in the digital age and the conventional way by which teachers think English should be taught and learned, unfortunately, still exists. The fact that today's EFL learners are more engaged in the virtual world than in traditional English classrooms cannot go unnoticed (see Warschauer, 2002). Gee (2008) indicated that virtual reality afforded by multi-user virtual environments (MUVEs) could suit the learning styles and interests of language learners and further enhance their experiential learning experiences and outcomes. Second Life (SL), for example, is one of the 3D MUVEs where avatars can interact and co-construct knowledge with other avatars through their immersion in various forms of real-life (RL) simulations. 3D MUVEs allow learner avatars to simulate real-world tasks in the virtual space (e.g., ask and follow directions on a city map, visit a museum, order food in a restaurant), which further accommodate Millennials' tech-oriented, multitasking, and creative learning styles (Dede, 2005; McGlynn, 2005).

Unique features afforded by MUVEs - such as 3D RL interaction, meaningful real-time collaboration, and virtual community building manifested in tele- and co-presence - have drawn growing attention from both practitioners and researchers (e.g., Cooke-Plagwitz, 2008; Wehner, Gump, \& Downey, 2011) to explore 3D MUVEs as a potential teaching and research arena that goes beyond traditional language classroom walls. Nevertheless, compared with existing computer-assisted language learning (CALL) research in asynchronous and synchronous environments, full-blown empirical studies that connect second language acquisition (SLA) to 3D MUVEs, such as SL, are still needed in current CALL literature as indicated in Peterson's study (2010a). We need more evidence-based studies (cf. Deutschmann, Panichi, \& Molka-Danielsen, 2009; Jauregi, Canto, de Graaff, Koenraad, \& Moonen, 2011; Peterson, 2006) to verify whether MUVEs can be conducive to learners' language use - before we can make positive claims that SL can serve as an optimal environment for learners' SLA to take place.

Motivated by task-based instruction from the standpoint of cognitive interactionist theory, this case study investigated how EFL learners use communication strategies to negotiate meaning during task-based interaction in SL. It is hoped that it contributes to the body of knowledge of whether SL can open up a 
new avenue for CALL research and provide both theoretical and pedagogical implications for language learning and teaching.

\section{SL for language learning and teaching}

SL was developed and initially launched by Linden Lab in 2003. According to the statistics report released by Linden Lab (2013), SL has attracted over 36 million registered users worldwide and still continues to grow in popularity. In SL, every user is called a resident, who can create his/her own 3D avatar to represent his/her virtual identity. Avatars can walk, run, fly (see Figure 1), teleport (i.e., instantly arriving in a new in-land location) and communicate via text or voice chat using a headset or built-in microphone. Avatars can also collaborate in real time (e.g., building a 3D object together). Additionally, avatars can demonstrate non-verbal gestures, such as laughing, making faces, crossing legs, and clapping. However, those non-verbal cues are not automatically signalled as in a RL face-to-face context and need to be manually configured by the avatar user.

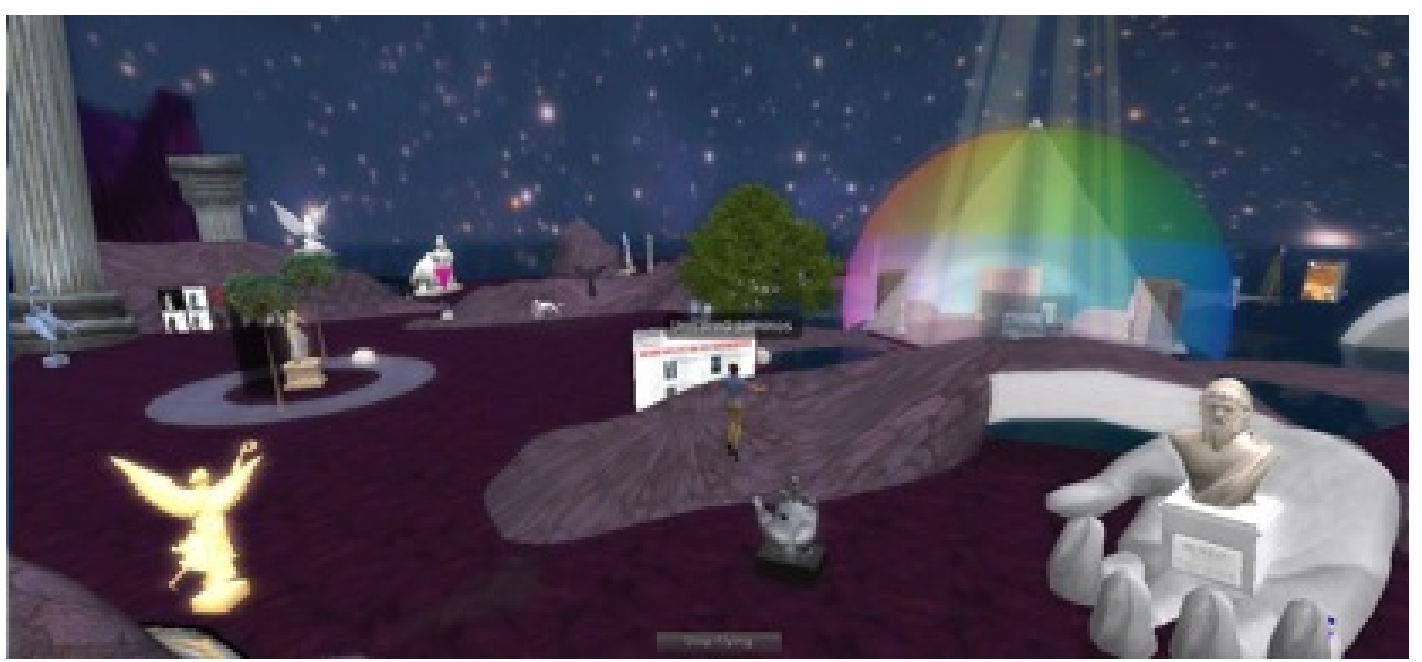

Figure 1. An avatar user flying to a 3D sculpture museum in SL

In SL, language learners can use both voice and text chats to practise their speaking and writing in different simulated RL tasks (see Silva, 2008). As Vickers (2007) pointed out, being able to use avatars to simultaneously collaborate and interact with other residents in the target language also gives them the opportunity to use authentic language as if they were in real-world scenarios.

The affordance of enabling learners to use multimodal tools to conduct RL tasks through 3D interaction in SL has also piqued the interests of researchers and teachers to explore the research and pedagogical potential of this 3D sphere. Research findings have revealed positive effects of SL on boosting learners' motivation and lowering anxiety towards foreign language learning (Wehner et al., 2011), enhancing learners' oral participation and engagement under collaborative and authentic task design (Deutschmann et al., 2009), promoting the construction of cultural identity and development of intercultural literacy (Diehl \& Prins, 2008), and optimising life-like task completion that leads to rich oral interaction and communicative competence (Jauregi et al., 2011).

In EFL contexts, opportunities provided for EFL learners to regularly experience life-like oral interaction with native speakers (NS) are unfortunately less favourable. Even though online English learning platforms are available to these learners nowadays, "the impersonal nature of text-based, often asynchronous course communications can create difficulties for students who desire a sense of community and involvement from their course interactions" (Cooke-Plagwitz, 2008, p. 548). The unique co-presence feature in SL - the sense of being there together in real time via 3D avatar representation has hence attracted EFL scholars to examine whether SL could maximise learners' language learning outcomes and the feasibility of incorporating SL in EFL teaching settings. Studies have also shown that the unique affordances in SL are beneficial for developing EFL learners' oral proficiency (Wang, Song, Stone, \& Yan, 2009), promoting positive attitudes towards English teaching and learning in 3D MUVEs 
(Liou, 2012), and stimulating more strategy use (e.g., interactional and transactional strategies) during task-based interaction via text chat (Liang, 2012; Peterson, 2010b).

Despite the positive claims, few studies have examined how EFL learners use communication strategies during task-based negotiation via voice chat in SL. Also, empirical studies that are framed by the interactionist theory and incorporate salient SL features in the task design (e.g., implementing object building function in the task of information gap) are needed in the realm of 3D MUVE research. As Peterson (2010b) pointed out, "[r]esearch on the use of 3D virtual worlds in CALL is limited, and many areas remain unexplored" (p. 274). Taking these research and pedagogical concerns into consideration, this study aimed to make sense of the patterns of EFL learners' oral discourse in their employment of communication strategies during task-based negotiation in SL.

\section{Theoretical framework}

This research study is framed by cognitive interactionist theory that informs the research purposes and task-based language teaching that guides the research design.

\section{Cognitive interactionist theory}

The nature of interactivity configured in computer-mediated communication (CMC) tools (e.g., text and voice chats) can be conceptualised and operationalised in the interactionist theory from the standpoint of cognitive SLA. Long (1981) argued that input alone is not sufficient for learners' language acquisition to occur. Schmidt (1990) and Gass (1997) also pointed out that learners need to notice the saliency in the input and attend to the gap during their interaction with NS, thereby turning input into more useful intake that has the opportunity to be incorporated in their current language system.

Another interactional component that is vital for acquisition to occur is negotiation of meaning, as indicated by SLA researchers (e.g., Gass \& Selinker, 2001; Long, 1983; Long \& Porter, 1985). Long (1996) asserted that "negotiation for meaning, and especially negotiation work that triggers interactional adjustments by the NS or more competent interlocutor, facilitates acquisition because it connects input, internal learner capacities, particularly selective attention, and output in productive ways" (pp. 451-452). Swain (1985) hypothesised that when learners interact with more advanced learners or NS, the communication breakdown will push them to notice the hot spot (e.g., a grammatical or phonological error that causes mis-/non-understanding) in their existing language repertoire. Consequently, learners will test their hypothesis of their current linguistic system by modifying their output to make it more comprehensible to interlocutors in order to resolve the non-understanding (see Swain's (1995) output hypothesis; Swain \& Lapkin, 1995).

Pica (1987) further implicated that the link between "interactional modifications" and "negotiation of meaning" that optimise learners' second language (L2) acquisition should be created. In order to repair the communication breakdown that occurs during the process of negotiated interaction between learners and nonnative peers or NS, the employed "conversational strategies" - such as repetition, confirmation checks, comprehension checks and clarification requests - are crucial for learners' L2 acquisition to take place (Pica, 1987, p. 74). The interactional modifications of the input signalled by the interlocutor and received by the learner not only help the latter repair his/her troubled spots at his/her current interlanguage level, but more effectively promote the quality of intelligibility of the output. They can further internalise those linguistic elements for better accuracy and refine their existing language system.

\section{Task-based language teaching (TBLT)}

TBLT has been increasingly adopted in both ESL and EFL contexts - due to its pedagogical potential for learners to use English for meaningful and authentic purposes through communicative, meaning-focused tasks that are associated with RL tasks (see Skehan, 2003). Aligning with cognitive and interactionist SLA theory (Long, 1985; Pica \& Doughty, 1985; Swain, 1995), Doughty and Long (2003) offered 10 methodological principles that guide the design of TBLT, particularly in a distance-learning environment (p. 52): 
(1) Use tasks, not texts, as the unit of analysis.

(2) Promote learning by doing.

(3) Elaborate input (do not simplify; do not rely solely on "authentic" texts).

(4) Provide rich (not impoverished) input.

(5) Encourage inductive ("chunk") learning.

(6) Focus on form.

(7) Provide negative feedback.

(8) Respect "learner syllabuses"/develop-mental processes.

(9) Promote cooperative/ collaborative learning.

(10) Individualize instruction (according to communicative needs and psycholinguistically).

These guidelines pinpoint that the TBLT design of instructional materials and tasks is based on a theoretically grounded framework that taps into interactive and real-world tasks, which can stimulate spontaneous language use and realise language acquisition in authentic discourses, rather than on proven fact. This is particularly crucial if viewed in EFL contexts where opportunities for two-way negotiated interaction and using English for communicative and meaningful purposes are still constrained by the grammar-oriented instruction that usually drives English education in most EFL contexts (e.g., Silver, $\mathrm{Hu}, \&$ Iino, 2002). A well-planned TBLT design that is driven by key elements of cognitive interactionist theory (e.g., negotiated instruction, comprehensible input and output) and grounded in methodological principles (e.g., task-oriented, communicative and real-world materials) can nevertheless enhance the cognitive and interactional processes of EFL learners that lead to optimal L2 language acquisition.

It has also been documented in CMC research (Chapelle, 2007; Jarvis, 2005; Peterson, 2006) that both asynchronous and synchronous CMC environments can facilitate the implementation of TBLT and promote spontaneous language use that transcends the physical limitations set by a traditional language class and offer students opportunities to carry out RL tasks for communicative purposes. Nevertheless, the extent to which TBLT can also be operationalised in 3D MUVEs and whether a TBLT design that incorporates communication tasks in SL could provide a pedagogical model to optimise EFL learners' language acquisition is worth investigating.

\section{Research rationale}

In order to gather empirical evidence to address "What oral discourse samples can be found in EFL learners' language practices in SL to indicate that SL can be a viable language learning environment," this case study aimed to investigate the extent to which EFL learners employ communication strategies to negotiate meaning during task-based interaction via voice chat in SL. The rationale of conducting voicebased interaction research in SL is informed by both theoretical and pedagogical concerns as follows:

- Finding an English NS to practise speaking on a daily basis is usually not realistic in most EFL contexts. Using voice chat to practise English with other avatars in SL without the restrictions of time and distance has attracted many EFL learners to this new 3D learning arena - as the case in this study. As such, providing them with the chance to practise speaking during task-based interaction had met their learning needs and interests. Participants in this study were therefore informed to use voice chat only to accomplish each communicative task, which suited their learning goal and the focus of the study.

- Since EFL learners can use voice chat to interact with other avatars in SL, the cognitive interactionist theory provides an optimal framework for this study. This study also intended to examine whether EFL learners in SL also use similar interactional modifications during the process of negotiation to make their language output more comprehensible - as much as they would do in prior interactionist research (e.g., Gass \& Selinker, 2001; Long \& Porter, 1985; Pica, 1987; Swain \& Lapkin, 1995). Due to the scarcity of voice-based interaction research in 3D MUVEs, it also aimed to validate whether EFL learners' communication strategy patterns through text-based interaction found in previous MUVE research (e.g., Peterson's (2006) study in Active Worlds and later in SL (Peterson, 2010b)) could also be evidenced through voicebased interaction in this study.

- Voice-based interaction is the focus of this study since research attention has been paid mostly to text chat in synchronous CMC studies (e.g., Lee, 2002; Smith, 2003) - much less in 3D MUVEs. 
Additionally, allowing participants to use text chat for task-based interaction would have counteracted the fact that learners' negotiated turn-takings via voice chat would not have been prompted to the extent as using one communication mode only - since they could resort to the other mode (text chat) to compensate for their non-understanding/confusion during voice-based negotiation.

\section{Methodology}

Due to space constraints, this study will only report the pre-and-post-course task interactions in a 10session virtual course from a large-scale dissertation study. Findings drawn from the task-based instruction during the virtual course over time will be presented elsewhere.

\section{Setting}

This case study was conducted in VIRTLANTIS, a 3D virtual island in SL. VIRTLANTIS offers all kinds of free language courses - which have attracted a growing number of language learners who are keen to improve their target language skills as well as language teachers who are willing to help those learners in SL. The creator of VIRTLANTIS granted volunteer teachers of languages free access to all the in-land resources to facilitate their teaching. Various interactive and 3D resources available in VIRTLANTIS have made teaching in SL different from that in RL. For instance, avatars could rez (i.e., create or make an object visible) Holodecks to simulate a myriad of RL scenarios (e.g., pizzeria), Skytable to conduct pair discussion in mid-air floors, or Sandbox to practise building 3D objects. Figure 2 displays a screen capture of VIRTLANTIS in SL.

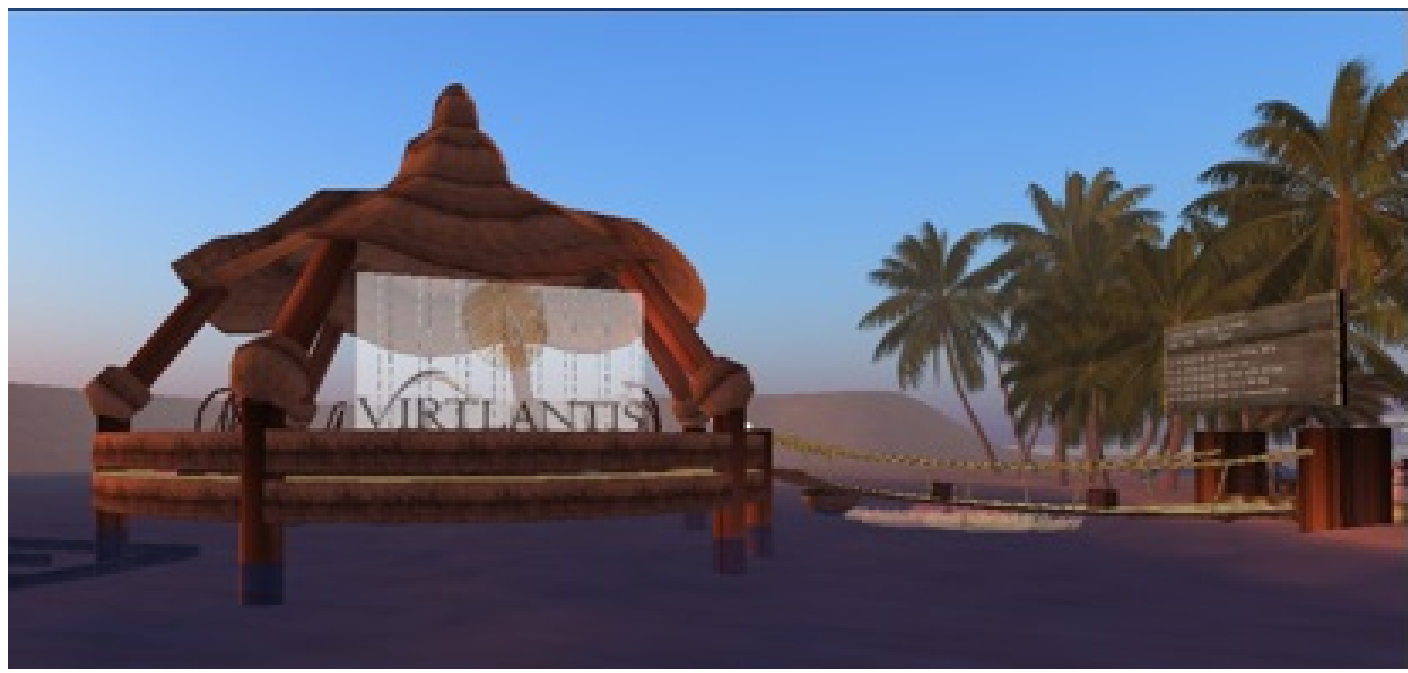

Figure 2. The entry point of VIRTLANTIS island

\section{Participants}

Nine EFL learners worldwide who were interested in practising their oral English in SL participated in this study. Some of the students were recruited through an SL instructor whose former students had finished taking an SL course with him. An invitation notecard was also sent out to all the members in VIRTLANTIS and Cypris Chat (another island for language learning and teaching). The notecard included the course objectives and purpose of this study and invited those who were interested to join the virtual class in SL.

Participants were all adult residents in SL. They were mostly experienced SL users whereas some were SL newbies who registered an SL account in order to join this virtual course. Before the virtual course, each participant was scheduled for a debriefing session in SL where his/her informed consent was also collected. Their levels of language proficiency ranged from beginner to upper-intermediate based on the initial oral proficiency screening in the pre-course task interaction. The detailed demographic information about the participants' gender, age range, proficiency level, native language, prior English learning 
experience in RL and SL, and reason(s) to attend this virtual course can be accessed at http://goo.gl/glHT0J.

\section{Data collection}

\section{Communication tasks}

Under the TBLT framework, four types of tasks were designed to elicit participants' use of interactional modification strategies during negotiation of meaning via voice chat in SL: opinion-exchange, information gap, jigsaw, and decision-making. There were two sets of the tasks provided in the precourse phase and post-course phase. In order to make both sets of tasks comparable and avoid the "practice effect" (Mackey \& Gass, 2005, p. 116), the task scenarios in the first set were RL-related (before the virtual course) while those in the second set were SL-related (after the virtual course) and incorporating SL features (e.g., object building).

In the opinion-exchange tasks, participants were asked to discuss their opinions on which English skill they thought was most difficult to learn (set one), and on how they compared learning English in RL and SL (set two). In the information gap tasks, participants took turns to direct their dyad partners to a location on a RL city map (set one), and instruct their partners to build an object in SL step by step following a notecard procedure (set two). In the jigsaw tasks, each dyad held an identical picture where they had to work together to spot the differences in both sets. In the final decision-making tasks, paired participants had to reach an agreement on which restaurant to dine at based on two RL restaurant menus (set one), and which gift to buy for their classmate's birthday party in SL based on two SL commercial advertisements (set two). Sample task examples (e.g., information gap and jigsaw) in pre- and post-course sessions can be retrieved at http://goo.gl/SiB3tl

\section{Procedure}

The pre-course task-based interaction was conducted in SL right before the 10-session virtual course between 40 minutes and 1 hour, depending on how long each dyad completed all the tasks. Since participants came from all over the world in different time zones, it was difficult to manage the pairing based strictly on their proficiency level. For the sake of data collection, they were paired in five dyads for task interaction based on their availability to meet in SL instead. Each dyad used their avatars to interact with their partners via voice chat to complete each task. Their oral interaction samples were audiorecorded using the Audacity recording software installed on my laptop computer. They were also informed that the whole process would be audio-recorded for further data analysis, as addressed in their consent form. The discourse samples collected from the participants served as the baseline data to examine their use of communication strategies during negotiation of meaning, which were to compare with the data collected in the last virtual session. Students were also scheduled for another task-based interaction by the end of the course. Each student was paired with a different peer this time to enhance the authenticity and face validity of the oral output (as opposed to pairing students in the same dyad where they might have been used to the way their original peer talked). Their language output via voice chat was audio-recorded in a fashion similar to the pre-course session.

\section{Data analysis}

This study sought to examine learners' use of modification strategies during the process of task-based negotiation in SL. Three main communication strategies identified in interaction-based literature (see Pica \& Doughty, 1985) were adopted for the coding scheme (see Table 1) as follows:

(1) "Clarification requests: Expressions designed to elicit clarification of the preceding utterance(s), and consisted of wh-, yes-no, uninverted intonation, and tag question as well as statements such as I don't understand and Try again.

(2) Confirmation checks: Elicitations immediately following the previous speaker's utterance to confirm that the utterance has been understood or heard correctly.

(3) Comprehension checks: Expressions designed to establish whether the speaker's own preceding utterance has been understood by the addressee ... usually in the form of tag questions, repetitions with rising intonation of all or part of the utterance, or by questions such as Do you understand?" (pp. 119-120). 
Other types of modification strategies used by participants were also identified as coding categories to examine their language patterns in negotiation of meaning (also see Lee, 2002, p. 279). Table 1 displays the coding scheme of strategy use by EFL students in the four tasks in both pre-and-post task interactions by strategy type.

All the audio recordings were manually transcribed by the author and each strategy use was meticulously numbered and coded throughout all the transcribed data - following the coding scheme defined by each categorised strategy type (Table 1). To ensure the coding reliability, the researcher's colleague who is specialised in SLA was invited to code the pre-course interaction samples using the same coding scheme. A high inter-coder reliability was reached at around $90 \%$, and disagreements on coding were discussed and resolved before both coders proceeded with coding the rest of the data. Examples are provided in Table 1 to demonstrate how each discourse sample was identified and documented based on the definitions that categorised strategy types across tasks.

Table 1

Communication strategy types, definitions, and examples across four tasks in both task-based interactions

\begin{tabular}{|c|c|c|}
\hline Strategy type & Definitions & Examples \\
\hline Comprehension checks & $\begin{array}{l}\text { To ask yes-no questions, ask to } \\
\text { repeat the received information or } \\
\text { repeat with rising intonation }\end{array}$ & $\begin{array}{l}\text { - "You understand me?" } \\
\text { - "Can you repeat what I am } \\
\text { telling you?" } \\
\text { - "Do you know the circle? The } \\
\text { circle?" }\end{array}$ \\
\hline Confirmation checks & $\begin{array}{l}\text { To ask confirmation questions or } \\
\text { repeat with rising intonation }\end{array}$ & $\begin{array}{l}\text { - "Do you mean he has } \\
\text { - } \quad \text { "Romething on his head?" } \\
\text {-Rota?" }\end{array}$ \\
\hline Clarification requests & $\begin{array}{l}\text { To express confusion, ask for } \\
\text { repeating what was said, or request } \\
\text { further explanation on confusing } \\
\text { information }\end{array}$ & $\begin{array}{l}\text { - "I don't understand." } \\
\text { - "Repeat, please?" } \\
\text { - "What did you say? You agree } \\
\text { what?" }\end{array}$ \\
\hline Request for help & $\begin{array}{l}\text { To request peer's direct assistance } \\
\text { in further explaining unfamiliar } \\
\text { words or expressions }\end{array}$ & - “Can you write, please?" \\
\hline Self-correction & $\begin{array}{l}\text { To correct errors made on lexical, } \\
\text { grammatical or phonological items } \\
\text { within the same turn of utterance }\end{array}$ & $\begin{array}{l}\text { "And the three coordinate is } \\
\text { cuatro, zero ... Oh, no! Four, } \\
\text { zero" }\end{array}$ \\
\hline Topic shift & $\begin{array}{l}\text { To abandon the current topic and } \\
\text { abruptly shift to a new topic due to } \\
\text { the difficulty or unfamiliarity with } \\
\text { the former }\end{array}$ & $\begin{array}{l}\text { - "... forget about the right } \\
\text { picture. Just focus on the left } \\
\text { picture." }\end{array}$ \\
\hline Metacognitive strategy & $\begin{array}{l}\text { To verbalise one's thinking } \\
\text { process in order to make input } \\
\text { more organised and output more } \\
\text { comprehensible }\end{array}$ & $\begin{array}{l}\text { - "Hmm, let me see how I can } \\
\text { describe myself ..." }\end{array}$ \\
\hline Spell out the word & $\begin{array}{l}\text { To assimilate the feature of text } \\
\text { chat by orally spelling out the } \\
\text { word that causes confusion }\end{array}$ & $\begin{array}{l}\text { - "You need to build a tube, T- } \\
\text { U-B-E, a tube." }\end{array}$ \\
\hline
\end{tabular}

\section{Results}

The empirical evidence of EFL learners' use of different types of interactional strategies to resolve communication breakdowns in SL was discovered in this study. Communication strategies $(N=447)$ account for around $19 \%$ of overall turns $(N=2319)$ across tasks in both pre-and-post course task interactions. Table 2 summarises the frequency and percentage of the overall communication strategies across tasks. 
Table 2

The frequency and percentage of strategy use in both sessions

\begin{tabular}{lcc}
\hline Strategy type & Number of times strategy is used & $\begin{array}{c}\text { Percentage of all communication } \\
\text { strategies }\end{array}$ \\
\hline Comprehension checks & 73 & $16.3 \%$ \\
Confirmation checks & 184 & $41.2 \%$ \\
Clarification requests & 148 & $33.1 \%$ \\
Request for help & 18 & $4.0 \%$ \\
Self-correction & 11 & $2.5 \%$ \\
Topic shift & 6 & $1.3 \%$ \\
Metacognitive strategy \& & 7 & $1.6 \%$ \\
spell out the word & & \\
Total & 447 & $100 \%$ \\
\hline
\end{tabular}

Of all the abovementioned communication strategies, confirmation checks are the strategy that students used most frequently $(41.2 \%)$, followed by clarification requests $(33.1 \%)$ and comprehension checks (16.3\%). These three communication strategies account for $90 \%$ of the total use of strategies.

Followings are discourse examples of the strategies selected from the coded data to better illustrate how each strategy use was taking place during task-based interaction. The targeted communication strategy is shown in bold. All examples are from dyad exchanges and numbered accordingly. For example, discourse samples one, two, and three will be numbered as (1), (2), (3), and so forth hereafter. Also note that students' errors in their language output in the following examples were kept intact to show the authenticity. Each turn was numbered and coded only when the flow of the utterances in the turn-taking discourse was complete and the floor was shifted to the next interlocutor. Students' initials of their avatar names were used for ease of coding and presentation of the results. Pauses or ongoing utterances that were not related to the highlighted linguistic output were coded as "...". My note is in parenthesis.

\section{Confirmation checks}

The first example below is from the pre-course jigsaw task, spot the differences. One student asked her partner a confirmation question to check whether she understood correctly.

(1) Confirmation check: asking confirmation questions

1. A: Another difference, uh ... Ok, a guy in the picture in your left side, I can see that a guy sitting at the end of the class, he's wearing like horns ...

2. U: Hmm, you mean he has something on his head?

3. A: Yes, his head, like horns, or ...

4. U: Ok, that? (He is using the digital pen to circle it.)

5. A: Good. Yes, yes.

The other pattern of confirmation checks involves repeating parts of received utterance with rising intonation to seek further confirmation from the conversation partner. The example below is from the post-course information gap task of building an object. Here we see how a student repeated what he heard with rising intonation to signal whether he had understood the information correctly.

(2) Confirmation check: repeat parts of the peer's utterance with rising intonation

1. U: Then you need to rotate the object.

2. P: Rotate?

3. U: Yes. For X, you need to rotate it in the 352 degrees.

\section{Clarification requests}

The second most frequently used communication strategy is clarification requests. The following example is from the pre-course task of opinion exchange. The content deals with which English skill students thought was the most difficult. One student voiced her confusion about the information she heard and indicated that her partner needed to further clarify the meaning. 
(3) Clarification request: expressing confusion

1. F: Yea, mistake ... Sometimes I don't know, I don't know use which ... (long pause) ... sometimes I want to say something has happened but I used the tense is, was happening.

2. B: I don't understand.

3. F: Hmm, I always make the grammar mistake ...

4. B: The grammar? Yes ...

The other type of clarification strategy can be seen in the scenario where a student would ask the interlocutor to repeat the previous utterance that seemed unclear or confusing to him/her. The example below is from the pre-course task of spot the differences.

(4) Clarification request: asking for repeating what was said

1. I: Uh ... the woman in different class, on the upper arms ... the picture has draw (embroidery) but right picture there is no draw (embroidery) ...

2. N: Repeat, please?

3. I: In the shirt of the woman, in front of the class, uh ... do you see the arm left picture the left arm has the pen, but right picture, no pen on her, on her shirt.

The third type of clarification requests is characterised by signifying the confusing word or information received from the interlocutor, coupled by requesting further clarification. The following vignette is from the decision-making task in the pre-course interaction. Students needed to agree on a restaurant for dinner.

(5) Clarification request: requesting further explanation on confusing information

1. Ul: What time do we have to come back home?

2. M: We can go back home a quarter past 6 .

3. Ul: A quarter past $6 \ldots$ uh ... I also agree to half past 9 . And you?

4. M: I bet your pardon ... I didn't hear you. What did you say? You agree what?

5. Ul: I can go home at, uh, half past 9 . About half past 9.

6. M: Past 9? We'll be home at, uh, by 9. Yes. So you will be home, eh, half past 9. It will be ok, I think ...

\section{Comprehension checks}

A comprehension check usually occurs when student A asks his/her partner, student B, if student B has understood. That said, the use of tag questions - one of the strategy types that characterise comprehension checks in Long's (1980) research - was not found in the present study. The first type of comprehension checks is evident in the pre-course information gap task where students took turns directing peers to the final destination on a map. In addition, asking a partner to repeat what was said also characterises the post-course task of information gap, in which one student told his peer how to build a particular object.

(6) Comprehension check: yes-no questions

1. P: Ok, right now you are in the 34th street, ok, and in the Walnut ... You need to walk in the Walnut Street until 40th Street. You understand me?

2. T: No.

3. P: No, ok. Right now you're moving in the direction. Go to the right.

4. T: Go, go to the right.

5. P: Right on Walnut Street. And go ahead up to the street, 40, 40th Street, 40. Go ahead. The next one.

6. T: Oh ya, I see, 40

(7) Comprehension check: asking to repeat the received information

1. U: Ok, listen to me. If you just click on the ground, right click on the ground, and you will hit the

Build option ... Can you repeat what I am telling you?

2. P: No, but I don't understand you. I need to understand around.

3. U: Korobase, you need to make an object. Ok?

4. P: Yes, ok. 
Another type of comprehension check strategy, using repetition with rising intonation, is found in another interaction in the post-course task of object building.

(8) Comprehension check: repetition with rising intonation

1. T: Ok you rez tube, not cube, tube. Ok, do you know the circle, the circle?

2. B: Circle? Ok, one moment. (She is rezzing an object of the circle shape.)

3. T: It's not a circle, but tube, round, a 3D of a circle.

4. B: Oh, one moment ... Cylinder?

5. T: Ya ...

6. B: Ok, like a cylinder.

\section{Other strategies}

Although the rest of categorised communication strategies only account for one tenth of the overall strategy use across tasks, it is also worth noting how these strategies were employed. A request for help was triggered when a student couldn't figure out the meaning of unfamiliar words or expressions encountered during task interaction and desired direct assistance from his/her peer in order to move the discourse forward and finish the assigned task. The following pre-course decision-making task illustrates how one student asked for help with the meaning of the word sleeved, while they were negotiating on what to wear on a dinner date and were reminded that only voice chat was allowed.

(9) Request for help:

1. F: Ok, we have two choice. Long sleeved shirt or pants. So which you wear, which you will wear? You prefer to wear.

2. B: Yes ... Prefer wear?

3. F: Long sleeved shirt or pants. Which you prefer to wear?

4. B: This word (sleeved), I can't understand ... You can write, please? ((laugh))

5. F: No ... ((laugh)) ... Long sleeved, long sleeved shirt.

A self-correction strategy is used when a student is aware of his/her error, either in a lexical item, pronunciation, or a grammatical structure and intends to correct it within the same turn of utterance. The following example illustrates how a Spanish student tried to tell her peer how to build an object in the post-course task. Instead of saying the number 4 in English, she said "cuatro" in her native language and noticed the error right away by switching back to the target language.

(10) Self-correction:

1. B: $3,5,2$. The second coordinate is 3,2 , and 9 .

2. T: $3,2,9$, ok

3. B: And the three (third) coordinate is cuatro, zero ... Oh, no! Four, zero.

4. T: Four what?

5. B: Four, zero.

Topic shift is the least frequently used strategy among the used strategies. However, it is apparent during a task interaction when a learner abandons the current topic - which has been exhausted or too difficult and abruptly moves on to a new idea. The following post-course task of information gap reveals how a student tried to tell his partner where to find a difference in the two seemingly identical photos. He couldn't succeed in getting his meaning across and finally gave up (in turn 6) and decided to move on to the next one.

(11) Topic shift:

1. P: Yes, but are you speaking about the wall?

2. U: Sorry?

3. P: The wall? in the bottom? Uh ... you can see the wood in white and in the right picture, it's red.

4. U: No, you're talking about something, which is different.

5. P: Yes, but I understood that something is white in the left picture, and red in the right picture.

6. U: No, no, no, forget about the right picture. Just focus on the left picture (he confused right with left). Again, on the left side, you can see on the bottom of the picture, it is white. 


\section{Strategies that were not previously reported in MUVE literature}

Two types of strategies - found in the current study but not yet documented in the literature of task-based interaction in the $3 \mathrm{D}$ virtual world - were also identified. They were also not frequently used $(1.6 \%$ combined) but evident in both pre-and-post course interactions. The first one is related to a metacognitive strategy, evidenced in the pre-course task interaction of information gap when one learner verbalised her thinking process (i.e., how to make her points more clearly) in order to direct her peer to the final destination.

(12) Metacognitive strategy

1. F: ... the way you put is west. So I want you go to the north...Ok, the direction you go is west. Do you understand me? West ...

2. B: West? I can't know where is west, south or north.

3. F: Left of the building is west and right of the building is east. So now I want you go through ... Go to the north of the building ... Hmm, let me see how I can describe myself ... (long pause) ... There are four crossroads around the post office. Did you saw it? Barrabax? Can you hear me?

4. B: I can hear u but I don't understand you.

5. F: Ok, do you know a crossroad, cross-cross-crossroad.

6. B: Help? Please ....

7. F: Ok, crossing ... corner ... the corner of the post office ... Do you saw? Ok ... How can I express myself ((laugh)) ...

8. B: Help, help, please...((laugh)) ...

Due to the constraint of using voice chat only, some students developed a shortcut strategy by asking their peer to orally spell out the word, especially when it was new or unclear to them. This strategy use was found in the post-course task of object building where one student tried to help his partner distinguish between the objects tube and cube by spelling out the word tube.

(13) Spell out the word

1. P: Perfect. Now you need to do something different. You need to build a tube, T-U-B-E, a tube. So you need to rez an object. In that case, please, right click on the ground and choose Build or Create, ok?

2. U: Sorry, Korobase, you're going so fast. Should I build a tube?

3. P: Don't worry ... yes, a tube.

4. U: Ok, it's a tube here. (He is rezzing a cube, not a tube)

5. P: No no no, you put a tube, not a...cube. It's not a cube. It's a tube. T, like triangle, U-B-E.

6. U: Tube, you mean?

7. P: Tube, yes, tube. Not cube. Tube.

8. U: Ok.

\section{Discussion}

\section{Comparisons of strategy use in SL and prior research}

The findings presented above also corroborate the positive claims made by previous research on interactional modifications. Students in this study were allowed to use voice chat only, but not text chat to type emoticons as non-verbal cues to facilitate communication (see Peterson, 2006; Smith, 2003), or spell out key words to resolve lexical confusions. Without these text-based strategies available, students were pushed to utilise the strategies commonly used in face-to-face communication (e.g., confirmation checks) that were available to them via voice chat to tackle any communication issues similar to the RL interactional discourse. The three most frequently used strategies found in this study also echo Doughty and Pica's (1986) finding that these modification devices were proven to make input more comprehensible due to deeper cognitive processing of linguistic knowledge (also see Pica, Young, \& Doughty, 1987; Swain, 2000).

Similar to this study, comparing non-native students' repair moves in synchronous text and voice chat rooms, Jepson (2005) found not only that voice chat generated more turns in negotiation and repair moves than text chat, but clarification requests were used more often than other repair types. The use of 
clarification request has been supported by previous research (e.g., Nobuyoshi \& Ellis, 1993; Pica, Holliday, Lewis, \& Morgenthaler 1989) in that it prompts learners to refine their interlanguage with more target-like quality and quantity in later language production. Although both clarification requests and confirmation checks were found in Jepson's study, there was no evidence of comprehension checks and self-correction. Jepson (2005) justified the absence of the two repair moves by inferring:

Comprehension checks and questions are primarily pedagogical by nature (Long \& Sato, 1983), and are thus scarce in NNS electronic conversation ... Additionally, self-correction is largely dependent on the social context, and it may be that NNS electronic chats are not fora conducive to self-correction (Kormos, 1999). (p. 89)

The current study, however, suggests otherwise - comprehension checks were the third most used strategy, and self-correction also occurred, though not frequently (see evidence of discourse samples reported above). Non-native speaker (NNS) voice-based interaction in SL, in this case, did prompt students' use of comprehension checks in dyad task interaction to ensure the information was conveyed accurately; therefore, the comprehension check strategy was conducive to students' self-correction awareness, despite the constraint of voice chat only and the fast-paced flow of turn-taking routines similar to real-time oral conversation (cf. Fernández-García \& Martínez-Arbelaiz, 2003).

Interestingly, EFL students - when faced by a peer's avatar - were more concerned about correcting their linguistic mistakes in order to deliver the correct information required for the completion of a task, than about "face threatening" as Jepson indicated in his 2005 study (p. 89). This phenomenon also differs from prior research on NS-NNS interaction where NNS learners either tend to avoid requesting help in order to save face by not revealing the fact that their partners' information is not being understood (see Long \& Porter, 1985). On the contrary, NNS-NNS negotiated interaction in SL shares the interactional patterns of NNS-NNS groups in face-to-face contexts where NNS interlocutors - as Varonis and Gass (1985) have asserted - "have a shared incompetence" since they are not yet competent in the target language and therefore are more willing to recognise peers' repair moves during negotiation "without embarrassment" (p. 71).

When faced with mis-/non-understandings during task interaction, beginning-level students tended to use the request for help strategy more often than their advanced-level counterparts. For example, BL, a beginning student, frequently resorted to this strategy in the pre-course task interaction. However, her request for peer assistance during negotiation appeared less frequently in the post-course session. It could be that students in the latter phase had become more confident using multiple strategies to resolve the communication breakdown before asking for help. Delaying requesting for help also mirrored Pica's (1988) finding that learners are able to activate their linguistic repertoire and produce more target-like output.

Another type of strategy, topic shift, was also found when students gave up on the topic because it was too difficult to continue the negotiation process (cf. Lee, 2002). They shifted to a new topic to keep the conversation going. Self-correction strategy that was evident in the study showed that the learner's metalinguistic awareness was raised by noticing the differences of linguistic knowledge between their mother tongue and the target language (see Schmidt, 1990; Schmidt \& Frota, 1986) due to the process of code switching (cf. Kötter, 2003). The use of self-correction also verifies Swain and Lapkin's (1995) output hypothesis:

A learner will on occasion become aware of (i.e., notice) linguistic problems (brought to his/her attention either by external feedback (e.g., clarification requests) or internal feedback). Noticing a problem 'pushes' the learner to modify his/her output. (p. 373)

Noticing linguistic errors made in one's oral production in L2 - triggered by either negotiated feedback from interlocutors or self-reflection/monitoring, as in this case - is also documented in Kitade's (2000) synchronous, CMC text chat study.

Two strategies that had not been previously identified by task-based research in 3D virtual environments were discovered (cf. Peterson, 2006): metacognitive strategy and spell out the word. Metacognitive strategies were employed more often in the post-course stage. This might indicate that students were 
more attuned to consciously processing language input and output by regulating their cognitive processing of L2 knowledge to get their meaning across more effectively and comprehensibly (see Fuente, 2003; Oxford, 2011). Interestingly, while negotiating on a word that seemed troublesome to the peer due to its unfamiliarity or the issue of pronunciation, students tried to explore alternative strategies when commonly used strategies had been mustered unsuccessfully. Under the restriction of voice chat only, they found that orally spelling out the word triggering the lexical confusion could serve as an alternative. This phenomenon is also documented in Sauro's (2001) task-based CMC study examining learners' oral communication, where learners also used the written mode to support listening comprehension and express meaning.

In a virtual environment like SL - though students could still see and interact with peers using their 3D avatars - paralinguistic features (e.g., gestures or facial expression) in face-to-face communication as alternative strategies to complement oral interaction (cf. Kötter, 2003; Negretti, 1999; Peterson, 2006) were not available. It was clear that in the fast-paced, two-way task interaction, EFL students tended to attend more to the process of task completion than to the configuration of those non-verbal cues in real time.

\section{SL features that augment task-based interaction}

It has been demonstrated in this study that authentic tasks that are meaningful and purposeful can prompt more spontaneous discourse samples. Tasks that capitalise on SL features, such as object building, can make task-based interaction more linguistically and cognitively stimulating since students can simultaneously see the movement of a 3D object after being directed by their interlocutor through dyad interaction. It also boosts their sense of engagement and achievement by seeing a 3D object take form step by step, thereby increasing their enjoyment during the process of task completion. As such, incorporating the building task in SL as part of the task design not only generates more authentic discourse samples, but also facilitates the process of data collection by maximising the elicitation of discourse samples and participants' task engagement. This unique feature also sets SL apart from other $\mathrm{CMC}$ tools. That is, although learners can still conduct videoconferencing with peers via other CMC tools, such as Skype, they are still virtually away from each other without experiencing the avatar copresence for task collaboration as in SL. In other words, learners can immerse themselves in task-based interaction augmented by the 3D form in SL and co-construct meaning with their interlocutors via avatars as if they were in the same place, at the same time.

Switching between the mixed modes afforded by SL (i.e., to approximate the text chat function via voice chat) has also been evidenced in this study as an alternative strategy for EFL learners. Being pushed to use voice chat only, students in this study came up with a new strategy to mimic the text chat function in the oral form. The finding of this new strategy also supports that NNS learners, when engaged in negotiated interaction, often resort to multimodal resources for additional linguistic support available in a CMC or 3D virtual environment (e.g., Sauro, 2001). They mix both written and oral modes simultaneously by using textual input to support oral output in order to tackle the task demands and communication breakdowns.

By the same multimodal token, this study also discovered that students used a digital pen to highlight the route on a city map or accessed the building menu feature to display what a pyramid looked like in an object building task. Being able to see simulated objects during the interaction process in the 3D mode gives EFL learners more input enhancement (see Ellis, 2001; Skehan, 2003) and helps them notice the gap (either in lexicon or pronunciation; see Schmidt, 1990). Allowing students to manipulate rich language input in 3D multimodal resources in SL not only enhances their language use, but also provides more visual support to employ in their modification strategy toolkit.

\section{Implications and limitations}

Prior studies examining the strategy use in students' language output in 3D MUVEs are mostly textbased, as in most CMC studies. The lack of research on task-based negotiation via voice chat in 3D MUVEs may be due to the burdensome data recording and transcribing processes, since text chat logs can be automatically kept in students' computers and be more easily gathered. Task design operationalised in a 3D MUVE like SL is not only theoretically sound, but also pedagogically feasible. This empirical study 
exemplifies the design of communication tasks by capitalising on SL features (e.g., object building) to elicit spontaneous oral discourse samples, as well as comprehensively documents how voice-based interaction research can be carried out in SL.

Due to the difficulty of recruiting EFL participants in SL from which the participant pool was drawn, randomisation was not feasible in this study. Given the small sample size and convenience sampling procedure, the findings may not be generalised to other target groups (e.g., younger EFL learners) or educational settings (e.g., EFL high school), although most of them share similar EFL learning backgrounds and concerns. Additionally, participants in the study accessed their own computers to attend the virtual course in SL. Therefore, recording the text chat logs of students' interaction with peers was not as easy as in a controlled lab setting. Voice-based interaction, hence, demarcated the scope of the current study.

\section{Conclusion}

As evidenced in this study, communication tasks that are meaningful, authentic, and aligned with SL features can stimulate task-based interaction, foster motivation, retain task engagement, and consequently optimise learner language processing and output. Multimodal features, such as simultaneous utilisation of text, voice, non-verbal gestures and interaction with 3D objects, can also scaffold learners' target language acquisition (e.g., noticing the gap in lexicon or pronunciation) through visual input enhancement. The effects of the multimodal features afforded by SL deserve a closer look in future 3D MUVE research.

Taken together, it was not the intention of this study to equate traditional teaching inside the class walls with passé and 3D web-based virtual environments with innovation. Rather, this study aimed to suggest an alternative way of language teaching/learning in MUVEs to accommodate the diverse learning styles and interests of today's EFL learners. For them, SL transcends the real world boundaries in a costeffective way. Being able to immerse themselves, access multimodal features to gain visual support, see peers, and engage in moment-to-moment task collaboration in the same place (in avatar form), at the same time, is the incentive that drives them to SL for English learning. Nevertheless, more theoretical and practical research on task-based interaction in SL is still needed before we can make positive claims that SL can make a difference in EFL learners' language acquisition.

\section{References}

Chapelle, C. A. (2007). Technology and second language acquisition. Annual Review of Applied Linguistics, 27, 98-114. doi:10.1017/S0267190508070050

Cooke-Plagwitz, J. (2008). New directions in CALL: An objective introduction to Second Life. CALICO Journal, 25(3), 547-557.

Dede, C. (2005). Planning for Neomillennial learning styles. EDUCAUSE Quarterly, 1, 7-12. Retrieved from https://net.educause.edu/ir/library/pdf/eqm0511.pdf

Fuente, M. J. (2003). Is SLA interactionist theory relevant to CALL? A study of the effects of computermediated interaction in L2 vocabulary acquisition. Computer Assisted Language Learning, 16(1), 4781. doi:10.1076/call.16.1.47.15526

Deutschmann, M., Panichi, L., \& Molka-Danielsen, J. (2009). Designing oral participation in Second Life: A comparative study of two language proficiency courses. ReCALL Journal, 21(2), 206-226. doi:10.1017/S0958344009000196

Diehl, W. C., \& Prins, E. (2008). Unintended outcomes in Second Life: Intercultural literacy and cultural identity in a virtual world. Language and Intercultural Communication, 8(2), 101-118. doi:10.1080/14708470802139619

Doughty, C. J., \& Long, M. (2003). Optimal psycholinguistic environments for distance foreign language learning. Language Learning \& Technology, 7(3), 50-80. Retrieved from http://lit.msu.edu/vol7num3/doughty/default.html

Doughty, C. J., \& Pica, T. (1986). "Information gap" tasks: Do they facilitate second language acquisition? TESOL Quarterly, 20(2), 305-325. doi:10.2307/3586546

Ellis, R. (2001). Non-reciprocal tasks, comprehension and second language acquisition. In M. Bygate, P. Skehan, \& M. Swain, (Eds.), Researching pedagogic tasks second language learning, teaching and 
testing (pp. 49-74). London: Pearson.

Fernandez-Garcia, M., \& Martinez-Arbelaiz, A. (2003). Learners' interactions: A comparison of oral and computer-assisted written conversation. ReCALL Journal, 15(1), 113-136. doi:10.1017/S0958344003000910

Gass, S. (1997). Input, interaction, and the second language learner. Mahwah, NJ: Erlbaum.

Gass, S., \& Selinker, L. (2001). Looking at the interlanguage process. In Second language acquisition: An introductory course (2nd ed., pp. 192-221). Mahwah, NJ: Erlbaum.

Gee, J. (2008). Game-like learning: An example of situated learning and implications for opportunity to learn. In P. A. Moss, D. C. Pullin, J. P. Gee, E. H. Haertel, \& L. J. Young (Eds.), Assessment, equity, and opportunity to learn (pp. 200-221). New York, NY: Cambridge University Press.

Jarvis, H. (2005). Technology and change in English language teaching (ELT). The Asian EFL Journal, 7(4), 213-227.

Jauregi, K., Canto, S., de Graaff, R., Koenraad, T., \& Moonen, M. (2011). Verbal interaction in Second Life: Towards a pedagogic framework for task design. Computer Assisted Language Learning, 24(1), 77-101. doi:10.1080/09588221.2010.538699

Jepson, K. (2005). Conversations - and negotiated interaction - in text and voice chat rooms. Language Learning \& Technology, 9(3), 79-98. Retrieved from http://lt.msu.edu/vol9num3/jepson/default.html

Kitade, K. (2000). L2 learners' discourse and SLA theories in CMC: Collaborative interaction in Internet chat. Computer Assisted Language Learning, 13(2), 143-166. doi:10.1076/0958-8221(200004)13:2;1D;FT143

Kötter, M. (2003). Negotiation of meaning and codeswitching in online tandems. Language Learning \& Technology, 7(2), 145-172. Retrieved from http://lit.msu.edu/vol7num2/kotter/default.html

Lee, L. (2002). Synchronous online exchanges: A study of modification devices on nonnative discourse. System, 30(3), 275-288. doi:10.1016/S0346-251X(02)00015-5

Liang, M.-Y. (2012). Reimagining communicative context: ELF interaction in Second Life to learn EFL. Journal of Language, Identity, and Education, 11(1), 16-34. doi:10.1080/15348458.2012.644118

Linden Lab. (2013, June 20). Infographic: 10 years of Second Life [Press release]. Retrieved from http://www.lindenlab.com/releases/infographic-10-years-of-second-life

Liou, H. C. (2012). The roles of Second Life in a college computer-assisted language learning (CALL) course in Taiwan, ROC. Computer Assisted Language Learning, 25(4), 365-382. doi:10.1080/09588221.2011.597766

Long, M. H. (1980). Input, interaction, and second language acquisition (Doctoral dissertation). University of California, Los Angeles.

Long, M. H. (1981). Input, interaction, and second-language acquisition. Annals of the New York Academy of Sciences, 379, 259-278. doi:10.1111/j.1749-6632.1981.tb42014.x

Long, M. H. (1983). Native speaker/non-native speaker conversation and the negotiation of comprehensible input. Applied Linguistics, 4(2), 126-141. doi:10.1093/applin/4.2.126

Long, M. H. (1985). A role for instruction in second language acquisition: Task-based language training. In K. Hyltenstam \& M. Pienemann (Eds.), Modelling and assessing second language acquisition (pp. 77-99). Clevedon: Multilingual Matters.

Long, M. H. (1996). The role of linguistic environment in second language acquisition. In W. C. Richie $\&$ T. K. Bhatia (Eds.), Handbook of research on language acquisition: Second language acquisition (Vol. 2, pp. 413-468). New York, NY: Academic Press.

Long, M. H., \& Porter, P. A. (1985). Group work, interlanguage talk, and second language acquisition. TESOL Quarterly, 19(2), 207-228. doi:10.2307/3586827

Mackey, A., \& Gass, S. (2005). Second language research: Methodology and design. Mahwah, NJ: Erlbaum.

McGlynn, A. P. (2005). Teaching millennials: Our newest cultural cohort. The Education Digest, 71(4), 12-16. Retrieved from ERIC database. (EJ741200)

Negretti, R. (1999). Web-based activities and SLA: A conversation analysis research approach. Language Learning \& Technology, 3(1), 75-87. Retrieved from http://llt.msu.edu/vol3num1/negretti/index.html

Nobuyoshi, J., \& Ellis, R. (1993). Focused communication tasks and second language acquisition. English Language Teaching Journal, 47, 203-210. doi:10.1093/elt/47.3.203

Oxford, R. L. (2011). The strategic self-regulation (S2R) model of language learning. Teaching \& researching: Language learning strategies (pp. 5-60). London: Pearson.

Peterson, M. (2006). Learner interaction management in an avatar and chat-based virtual world. Computer Assisted Language Learning, 19(1), 79-103. doi:10.1080/09588220600804087 
Peterson, M. (2010a). Massively multiplayer online role-playing games as arenas for second language learning. Computer Assisted Language Learning, 23(5), 429-439. doi:10.1080/09588221.2010.520673

Peterson, M. (2010b). Learner participation patterns and strategy use in Second Life: An exploratory case study. ReCALL, 22(3), 273-292. doi:10.1017/S0958344010000169

Pica, T. (1987). Second-language acquisition, social Interaction, and the classroom. Applied Linguistics, 8(1), 3-21. doi:10.1093/applin/8.1.3

Pica, T. (1988). Interlanguage adjustments as an outcome of NS-NNS negotiated interaction. Language Learning, 38, 45-73. doi:10.1111/j.1467-1770.1988.tb00401.x

Pica, T., \& Doughty, C. J. (1985). Input and interaction in the communicative language classroom: A comparison of teacher-fronted and group activities. In S. M. Gass \& C. Madden (Eds.), Input in second language acquisition (pp. 115-132). Rowley, MA: Newbury House Publishers.

Pica, T., Holliday, L., Lewis, N., \& Morgenthaler, L. (1989). Comprehensible output as an outcome of linguistic demands on the learner. Studies in Second Language Acquisition, 11(01), 63-90. doi: $10.1017 / \mathrm{S} 027226310000783 \mathrm{X}$

Pica, T., Young, R., \& Doughty, C. (1987). The impact of interaction on comprehension. TESOL Quarterly, 21, 737-758. doi:10.2307/3586992

Sauro, S. (2001). The success of task type in facilitating oral language production in online computer mediated collaborative projects (Unpublished master's thesis). Iowa State University, Ames.

Schmidt, R. (1990). The role of consciousness in second language learning. Applied Linguistics, 11, 129158. doi:10.1093/applin/11.2.129

Schmidt, R., \& Frota, S.N. (1986). Developing basic conversational ability in a second language: A case study of an adult learner of Portuguese. In R. Day (Ed.), Talking to learn: Conversation in second language acquisition (pp. 237-326). Rowley, MA: Newbury House.

Silva, K. (2008). Second Life. TESL-EJ, 12(1), 1-6. Retrieved from http://www.cc.kyotosu.ac.jp/information/tesl-ej/ej45/m1.pdf

Silver, R. E., Hu, G., \& Iino, M. (2002). English language education in China, Japan, and Singapore. Singapore: National Institute of Education, Nanyang Technological University.

Skehan, P. (2003). Task-based instruction. Language Teaching, 36, 1-14. doi:10.1017/S026144480200188X

Smith, B. (2003). Computer-mediated negotiated interaction: an expanded model. The Modern Language Journal, 87, 38-57. doi:10.1111/1540-4781.00177

Swain, M. (1985). Communicative competence: Some roles of comprehensible input and comprehensible output in its development. In S. Gass \& C. Madden (Eds.), Input in second language acquisition (pp. 235-253). Rowley, MA: Newbury House Publishers.

Swain, M. (1995). Three functions of output in second language learning. In G. Cook \& B. Seidlhofer (Eds.), Principle and practice in applied linguistics: Studies in honor of H. G. Widdowson (pp. 12544). Oxford: Oxford University Press.

Swain. M. (2000). The output hypothesis and beyond: Mediating acquisition through collaborative dialogue. In J. P. Lantolf (Ed.), Sociocultural theory and second language learning (pp. 97-114). Oxford: Oxford University Press.

Swain, M., \& Lapkin, S. (1995). Problems in output and the cognitive processes they generate: A step towards second language learning. Applied Linguistics, 16, 370-391. doi:10.1093/applin/16.3.371

Varonis, E., \& Gass, S. M. (1985). Non-native/Non-native conversations: a model for negotiating meaning. Applied Linguistics, 6(1), 71-91. doi:10.1093/applin/6.1.71

Vickers, H. (2007, September 12). Second Life education gets real: New methods in language teaching combine virtual worlds with real life. Avatar Languages. Retrieved from http://www.avatarlanguages.com/pressreleases/pr3 en.php

Wang, C. X., Song, H., Stone, D. E., \& Yan, Q. (2009). Integrating Second Life into an EFL program in China: Research collaboration across the continents. TechTrends: Linking Research \& Practice to Improve Learning, 53(6), 14-19. doi:10.1007/s11528-009-0337-z

Warschauer, M. (2002). Reconceptualizing the digital divide. First Monday, 7(7). Retrieved from http://firstmonday.org/htbin/cgiwrap/bin/ojs/index.php/fm/article/view/967/888

Wehner, A. K., Gump, A. W., \& Downey, S. (2011). The effects of Second Life on the motivation of undergraduate students learning a foreign language. Computer Assisted Language Learning, 24(3), 277-289. doi:10.1080/09588221.2010.551757 
Corresponding author: Julian ChengChiang Chen, Julian.Chen@curtin.edu.au

Australasian Journal of Educational Technology (C) 2016.

Please cite as: Chen, J C. (2016). EFL learners' strategy use during task-based interaction in Second Life. Australasian Journal of Educational Technology, 32(3), 1-17. 